Short Communication

\title{
'When the dog bites': What can we learn about health geography from newspaper coverage in a 'model city' for dog-bite prevention?
}

\author{
M. Mouton ${ }^{\mathrm{a}, *}$, A. Boulton ${ }^{\mathrm{b}}$, O. Solomon ${ }^{\mathrm{c}, \mathrm{d}}$, M.J. Rock ${ }^{\mathrm{a}, \mathrm{b}}$

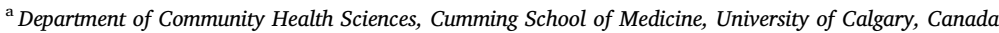 \\ ${ }^{\mathrm{b}}$ Faculty of Social Work, University of Calgary, Canada \\ ${ }^{\mathrm{c}}$ University of Southern California University Center for Excellence in Developmental Disabilities at Children's Hospital Los Angeles, USA \\ ${ }^{\mathrm{d}}$ Department of Pediatrics, Keck School of Medicine, University of Southern California, USA
}

\section{A R T I C L E I N F O}

\section{Keywords:}

Injury

Prevention and control

Environmental policy

Animal behaviour

Urban health

Communications media

\begin{abstract}
A B S T R A C T
Despite calls for the adoption of 'One-Health' approaches, dog-bite injuries remain neglected in healthcare and public health, and our study may help to understand why. Media coverage can influence policy directions, including policies that address dogs. We collected articles $(n=65)$ published in two local newspapers, 2012-2017, then carried out an ethnographically-informed discourse analysis of the dog-bite reports. The newspapers portrayed dog-bites mainly as matters of public disorder, as opposed to priorities for healthcare and public health. Even as our study took place in a city that has shown dog-bite reductions without recourse to 'breed bans' or restrictions (i.e., breed-specific legislation), journalists still tended to emphasize dog breed as a narrative element in explaining dog-bite incidents. Nonetheless, the news coverage did not reproduce a 'nature versus nurture' dichotomy. Rather, the journalists presented dog breed, and presumably associated aggressive behaviour, as entanglements with social, economic, and cultural contexts. Meanwhile, the news stories reduced contextual complexity to geographic locations, as codes for community reputation, in attributing causality and morality.
\end{abstract}

\section{Introduction}

Interest continues to grow in 'One Health' approaches (Friese and Nuyts, 2017) that address "global and inter-species sharing of health concerns and interests" and that "join up areas of expertise and practice, which have for too long existed in separate silos" (Hinchliffe and Craddock, 2015: 1). Dog-bite injuries offer a good opportunity to operationalise this research agenda because they involve a plurality of actors - both human and non-human (Rock et al., 2007). In addition, dog-bite injuries straddle policing and public health (Timmermans and Gabe, 2002). Nonetheless, public health researchers and healthcare providers have tended to ignore this issue (Duperrex et al., 2009; Ozanne-Smith et al., 2001), as well as the negative impacts that aggressive dogs can have on physical activity and social well-being in communities (Toohey and Rock, 2011). In this article, we approach the question of dog-bite injuries from the standpoint of media reports, given the potential for journalists to influence policy agendas and to frame the terms of political debates (Kingdon, 1984; Krcatovich and Reese, 2017).
Consequently, our qualitative analysis focuses on how journalists portray dog-bite incidents, whereas previous research has mined media coverage for epidemiological insights regarding dog-bite injuries and fatalities (e.g., Podberscek, 1994; Raghavan, 2008). Conceptually speaking, we analyse these 'human interest' stories (Hughes, 1937) as discursive events (Foucault, 1969), whose form and content are matters of power (Foucault, 1971). Operationally, we mobilised framing theory (Altheide, 1987; Baker et al., 2008; Entman, 1993; Wodak and Meyer, 2009), while also paying attention to the conditions of production of local news (Altheide, 1987; Bourdieu, 1994). Our goal was to understand ideas in public circulation about dog-bite causes, culpability, and responsibility. Little attention has been paid to how journalists describe dog-bite incidents, and that is what we do. Understanding the interpretive frames in media coverage could be helpful for public health actors to reshape public debates and, ultimately, to promote health through better-tailored and more effective policies for dog-bite prevention.

Overall, we found that the journalists in our setting portrayed dogbites as social deviance. They 'made do' with limited information,

\footnotetext{
* Corresponding author. Department of Community Health Sciences, Cumming School of Medicine, University of Calgary, 3E13 - Teaching, Research and Wellness Building, 3280 Hospital Drive NW, Calgary, AB, T2N 4Z6, Canada.

E-mail address: morgan.mouton@ucalgary.ca (M. Mouton).
} 
which usually included dog breed and the location where dog-bite incidents occurred. Using these elements, journalists wrote stories that portrayed dog-bite problems as social in nature, even while referring to dog breed. The reports tended to be brief, only a few paragraphs in length, and few incidents were subject to follow-up reporting. Of note, the geographic location of dog-bite incidents received emphasis in our corpus. Given that the journalists did not raise questions about the role of social inequalities in dog-bite injuries, we suggest that this emphasis on physical and social geography perpetuates negative reputations of disadvantaged communities.

\section{Methodology}

This study is part of a larger project that focuses on dog-related policy in Calgary, Alberta. This city is well known, in Canada and internationally (Rock et al., 2014; Parliament of Victoria, 2016), for reducing dog-bite injuries and dog-aggression incidents without recourse to breed-specific legislation (BSL). BSL takes various forms, but always entails banning or imposing restrictions based on the ancestry or appearance of dogs (e.g., pitbulls). This type of policy has been evaluated in several places, with mixed results (Clarke and Fraser, 2013; Cornelissen and Hopster, 2010; MacNeil-Allcock et al., 2011; Ott et al., 2008; Raghavan, 2008; Súilleabháin, 2015). In light of this policy debate, we were interested in the journalistic treatment of breed in the coverage of dog-bite incidents.

We collected items on dog-bites from two local newspapers, The Calgary Herald and The Calgary Sun, published between 1 January 2012 and 31 December 2017. This time-frame reflected the availability of full-text articles in a digital format. We located these items via the Factiva $^{(}$database with the following search terms: dog bite* OR dog attack* OR canine bite* OR canine attack* OR dog maul* OR dog aggress*. MM and $\mathrm{AB}$ removed items that did not focus on dog-bites before saving the articles within $\mathrm{NVivo}^{\odot}{ }^{\odot}$, where they were sorted, read several times, and coded to help in identifying thematic and discursive properties (Green and Thorogood, 2018 [2004]).

Our analysis was refined during a two-day intensive meeting where $\mathrm{MM}$ and $\mathrm{AB}$ discussed the emergent analysis with OS and MJR. As part of the analysis, we used $\mathrm{NVivo}^{\odot}$ to produce a word-cloud of the 25 most-frequently used words in our corpus (see Fig. 1). To eliminate words offering little interpretative potential for our study (e.g., "one" and "two" were displayed initially), we limited the word-frequency query to words comprising four or more letters. We also homogenized the spelling of "pit-bull" and "pit bull" as "pitbull".

Meanwhile, $\mathrm{MM}$ and $\mathrm{AB}$ informally interviewed two former journalists about the conditions of production for local news. Several weeks

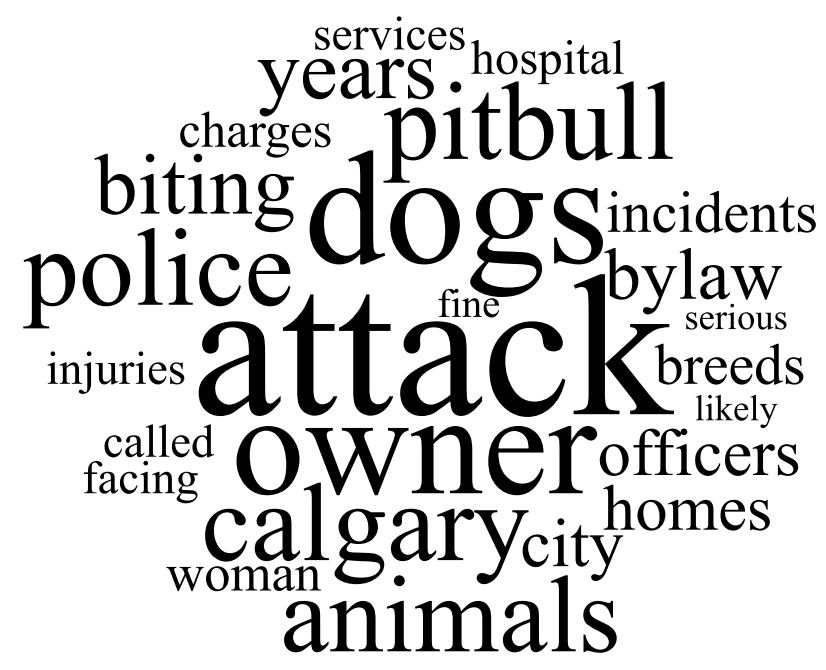

Fig. 1. The 25 most-frequently used words in the corpus.
Table 1

Overview of the corpus.

\begin{tabular}{lllll}
\hline & $\begin{array}{l}\text { News } \\
\text { Reports }\end{array}$ & $\begin{array}{l}\text { Columns and } \\
\text { Editorials }\end{array}$ & $\begin{array}{l}\text { Letters to the Editor } \\
\text { and Op-Eds }\end{array}$ & Total \\
\hline Calgary Sun & 71 & 8 & 1 & 80 \\
Calgary Herald & 51 & 2 & 1 & 54 \\
& & & & 134 \\
\hline
\end{tabular}

later, $\mathrm{MM}$ and $\mathrm{AB}$ conducted a follow-up interview with one of the former journalists. This follow-up interview was recorded digitally, transcribed by $\mathrm{AB}$, and reviewed by $\mathrm{MM}$. This dialogue helped to contextualise the media reports in our corpus, and also helped us understand the viewpoint of journalists.

Overall, our approach has been ethnographic in nature (Altheide, 1987; Katz, 2006), in that our analysis has drawn on careful readings of policy documents; previous research involving participant-observation and recorded interviews with animal-control officers; informal interactions with such officers, their managers, and healthcare providers; and everyday experience with dogs in the research setting and elsewhere. Our understanding also evolved as we prepared and presented a poster at professional conferences (attended by animal-control officers [MM and $\mathrm{AB}]$ and by paramedics [MJR], respectively), and as we drafted this article [MM, OS, MJR].

\section{Results and discussion}

In all, we found 133 items that met our inclusion criteria (Table 1). The majority appeared in The Calgary Sun $(\mathrm{n}=78)$, and the remainder in The Calgary Herald $(n=55)$. While they belong to the same holding corporation, and currently share a newsroom, these newspapers differ in terms of readership: The Calgary Sun is a 'tabloid', whereas The Calgary Herald is a 'broadsheet'.

Our argument revolves around elements that are visible in Fig. 1, and which we will present sequentially: the actors, the plot, and the stage.

\subsection{Public order vs. public health}

Dog-bite incidents were consistently framed as a socially deviant and disorderly occurrence, and as a policing issue, rather than as a public health problem. Consider the words that appeared most frequently in the news articles (see Fig. 1): the semantic field pertaining to policing ('police', 'officers', 'bylaw', 'charges', 'fine, 'facing') is much more prominent than that of health ('hospital', 'injuries'). In addition, descriptions of the dog-bite victims' injuries are often primarily presented in order to outline the severity of the incident, and the nature of consequences faced by aggressive dogs and their owners. The Calgary Sun article published under the headline, 'Charging pitbull mauls woman,' on 17 April 2014 illustrates these points:

A passerby called 911 and [the victim] was taken to hospital, where she underwent surgery. At home Wednesday, she said she is unable to walk and can't see out of her right eye. She's been forced to take at least three weeks off of work. The attack is categorized as a Level 5 [on the Dunbar scale, which the local council uses for administrative statistics and enforcement], just below the most severe type - Level 6 - which results in death, said [a bylaw officer]. He said the dog's owner was clearly shaken up after seeing the photos of [the victim]'s injuries and voluntarily signed the dog over for euthanasia.

\subsection{Journalistic treatment of breed in a city that does not endorse BSL}

Even as The City of Calgary has explicitly rejected BSL (Rock et al., 2014), and as animal-control officers deliberately minimise the role of 
breed in their public relations communications (Parliament of Victoria, 2016), ${ }^{1}$ every single article in our corpus mentioned breed. And within the treatment of dog breeds, 'pitbulls' were most prominent (see Fig. 1). Nonetheless, pitbulls accounted for $14 \%$ of dog-bite complaints to the City between 2012 and 2014 (City of Calgary, 2016, p.4).

Animal control officers who had been interviewed by journalists provided us with insight into this disparity. ${ }^{1}$ They said that journalists sometimes "discard" stories involving dog-breeds with positive reputations (e.g., poodles, huskies), focusing rather on the deeds of more "sensational" cases (e.g., pitbulls).

This observation resonates with a political critique authored by Kim (2015, p. 272), who contends that 'the pitbull is now raced Black in the American imagination.' Her argument is twofold. First, she makes a parallel between the way pitbulls are seen and African-Americans' experience of racism in the United States of America:

Like Blacks, pitbulls have been constructed as a group of beings whose behavior is biologically determined as violent, ruthless, and dangerous. [...] Like Blacks, they are objects of public loathing and fear whose very presence provokes a strongly disciplinary (if not murderous) response. (2015, p. 272).

In our corpus, 22 of 133 articles mentioned dog breed in the title itself - and in 20 of these 22 occurrences, the journalists described the dog as a pitbull. At the same time, the journalists demonstrated reflexivity about reducing dog-bite causation to breed, particularly in three opinion pieces. Put another way, our corpus displays more nuance than what Kim (2015) describes: dog breed was only one of several background narrative elements that reporters assembled in order to construct a story. The supposedly 'violent nature' of certain breeds is hinted at in conjunction with other background elements, notably the socio-economic status of dog-owners and communities.

The second part of Kim's (2015) argument is that the prejudices suffered by pitbulls and ethno-racial minorities can reinforce each other. This point applies to our corpus, and is best conveyed by an incident featured in 17 articles. Both newspapers in our study followed this story, from the dog-bite injury through to the sentencing of its main character. The story unfolded as follows:

- In August of 2012, a woman with 'severe injuries' was taken to hospital. Allegedly during an argument, a friend had ordered her two pitbulls to attack;

- Upon arrival, the police shot one of the pitbulls on sight, while the other was euthanized after being taken into custody;

- Meanwhile, the dog-owner fled and spent several days in hiding before her arrest. She was eventually convicted for aggravated assault and criminal negligence.

While none of the articles in our corpus directly mentioned ethnoracial identity, this information was conveyed through photographs, which revealed that the dog-owner was Black. The fact that her two dogs were both pitbulls amplified the sensationalist tone of the story. Journalists used evocative language to describe the 'deliberate savagery' that characterised this 'vicious attack,' but they did not apply these adjectives to the dogs or their owner specifically. In other words, the journalists played on ambiguity to offer several possible interpretations when it comes to attributing blame. Hence, descriptions of the human and non-human actors in this story tended to reinforce each other, to produce gripping accounts of the dog-bite incident and its consequences. Our findings point to the need for a systematic assessment of the congruence of representations ascribed to ethno-racial identities and dog-breeds in media reports.

Another element is striking as we analyse this story. In the articles

\footnotetext{
${ }^{1}$ Round-table in connection with the Alberta Municipal Enforcement Association Conference (May 8-11, 2017, Red Deer, AB).
}

we read, the scenery is set with the mention of the incident's location: a "Sundre trailer park." This example illustrates the prominent role of location in dog-bite coverage. In our corpus, we observe a frequent mention of the Northeast quadrant of Calgary (27 articles, as opposed to a cumulated amount of 47 articles for the three other quadrants). A high proportion of immigrants, especially from South and Southeast Asia, live in this quadrant, where the median income is substantially lower than the rest of the city (Townshend et al., 2018). Journalists tend to emphasize the location of dog-bite incidents that occurred in the Northeast quadrant, by mentioning it in the lead paragraph (13 out of 27 articles, as opposed to 14 out of 47 articles for the three other quadrants), for instance, or by stating it twice ( 9 out of 27 articles, as opposed to 6 out of 47 articles for the three other quadrants). For instance, the journalist might mention the community name, and later refer to a dog-owner or victim "in her Northeast home."

\subsection{Geographies of dog-bite coverage}

Our analysis reveals that breed is very much at the centre of newspaper portrayals of dog-bites, but in a subtler way than Kim's (2015) example suggests. The idea of 'inherently dangerous' breeds is present in journalists' depictions of the incidents they report on, but is used in conjunction with socio-economic status and sometimes ethnoracial elements, rather than as a single factor of explanation. Such a strategy puts the location of dog-bite incidents in a prominent position within the narratives, since it is an indirect, yet effective, way of disseminating information on the socio-economic background of the actors involved. As a consequence, we argue that dog-bite coverage relies on, but also contributes to, a negative reputation for some disadvantaged communities. The role of local newspapers in engendering community reputation has been well documented (Kearns et al., 2013; McLaren et al., 2005). The present article connects this phenomenon to previous scholarship (Derges et al., 2012; Tissot, 2011) that points to a role of dogs in shaping a neighbourhood's image.

\section{Conclusion}

By weaving together statements about the breed of the dog, photographs of the protagonists, and notes on the location of dog-bite incidents, journalists seem to engage in a 'blame game.' With few exceptions, the circumstances surrounding dog-bite injuries received little attention or follow-up in the newspapers that we studied. These results point to the need for researchers to question dog-bite causation, and to interrogate any assumptions about links between socio-economic status and an inability or unwillingness to control a dog.

Our study sets the stage for future research comparing media coverage with policy decision-making on dog-bites. As with media coverage in general, dog-related stories may influence public policies, and vice versa (Instone and Sweeney, 2014; Toohey and Rock, 2015). Despite calls for such research nearly twenty-five years ago (Podberscek, 1994), the interplay between media coverage and dog-bite policies remains opaque. Meanwhile, health researchers could elevate public understanding of dog-bites through media outreach. To do so, we recommend partnering with healthcare organisations (e.g., hospitals), animal welfare organisations, and local governments. Given that media coverage can assist with public education and awareness, cooperation between health researchers with stakeholders and journalists could provide an important perspective on policies and programs to reduce dog-bites and their negative impacts.

\section{Acknowledgements}

The authors would like to thank their research participants, who provided invaluable insights on the production of local news. We also benefitted extensively from discussions with Doug Anderson, at The City of Calgary, as well as other bylaw officers present at the Alberta 
Municipal Enforcement Association annual conference, where we first presented our results. Our paper also benefited from discussions at the inaugural Research Day for Alberta Emergency Services and the Alberta College of Paramedics. This research has built on previous research by our colleagues Niamh Caffrey, Sylvia Checkley, Dawn Rault, and Oliva Schmidtz, and we also benefited from consultations with Lorraine Toews in her capacity as liaison librarian for veterinary medicine at the University of Calgary. The main funder is the Social Sciences and Humanities Research Council of Canada (SSHRC) through an Insight Development Grant (\#430-2016-00078 to Rock and Solomon). In addition, this project benefitted from postdoctoral awards to Mouton from the University of Calgary's O'Brien Institute of Public Health and Cumming School of Medicine. This study received approval from the Conjoint Health Research Ethics Board at the University of Calgary.

\section{Appendix A. Supplementary data}

Supplementary data to this article can be found online at https:// doi.org/10.1016/j.healthplace.2019.03.001.

\section{References}

Altheide, D.L., 1987. Reflections: ethnographic content analysis. Qual. Sociol. 10, 65-77. Baker, P., Gabrielatos, C., Khosravinik, M., Krzyżanowski, M., McEnery, T., Wodak, R., 2008. A useful methodological synergy? Combining critical discourse analysis and corpus linguistics to examine discourses of refugees and asylum seekers in the UK press. Discourse Soc. 19, 273-306.

Bourdieu, P., 1994. L'emprise du journalisme. Actes de la Recherche en Sciences Sociales 101, 3-9.

City of Calgary, 2016. Animal \& Bylaw Services - Information for Australian Parliament (Victoria). pp. 7.

Clarke, N.M., Fraser, D., 2013. Animal control measures and their relationship to the reported incidence of dog bites in urban Canadian municipalities. Can. Vet. J. 54, $145-149$.

Cornelissen, J.M., Hopster, H., 2010. Dog bites in The Netherlands: a study of victims, injuries, circumstances and aggressors to support evaluation of breed specific legislation. Vet. J. 186, 292-298.

Derges, J., Lynch, R., Clow, A., Petticrew, M., Draper, A., 2012. Complaints about dog faeces as a symbolic representation of incivility in London, UK: a qualitative study. Crit. Public Health 22, 419-425.

Duperrex, O., Blackhall, K., Burri, M., Jeannot, E., 2009. Education of children and adolescents for the prevention of dog bite injuries. Cochrane Database Syst. Rev.(2).

Entman, R.M., 1993. Framing: toward clarification of a fractured paradigm. J. Commun. $43,51-59$.

Foucault, M., 1969. L'archéologie du savoir. éditions Gallimard, Paris.

Foucault, M., 1971. L'ordre du discours. (Paris).

Friese, C., Nuyts, N., 2017. Posthumanist critique and human health: how nonhumans (could) figure in public health research. Crit. Public Health 27, 303-313.
Green, J., Thorogood, N., 2018. Qualitative Methods for Health Research. Sage, Thousand Oaks, CA.

Hinchliffe, S., Craddock, S., 2015. One World One Health? Social science engagements with the one medicine agenda. Soc. Sci. Med. 129, 1-4.

Hughes, H.M., 1937. Human interest stories and democracy. Publ. Opin. Q. 1, 73-83.

Instone, L., Sweeney, J., 2014. Dog waste, wasted dogs: the contribution of human-dog relations to the political ecology of Australian urban space. Geogr. Res. 52, 355-364.

Katz, J., 2006. Ethical escape routes for underground ethnographers. Am. Ethnol. 33, 499-506.

Kearns, A., Kearns, O., Lawson, L., 2013. Notorious places: image, reputation, stigma. The role of newspapers in area reputations for social housing estates. Hous. Stud. 28, 579-598.

Kim, C.J., 2015. Dangerous Crossings: Race, Species, and Nature in a Multicultural Age. Cambridge University Press.

Kingdon, J.W., 1984. Agendas, Alternatives, and Public Policies. Little, Brown.

Krcatovich, E.M.S., Reese, L.A., 2017. Everyone loves a dog story: narratives of urban animal welfare policy. Social Problems 65 (3), 416-437.

MacNeil-Allcock, A., Clarke, N., Ledger, R., Fraser, D., 2011. Aggression, behaviour and animal care among pit bulls and other dogs adopted from an animal shelter. Animal Welfare UFAW J. 20, 463.

McLaren, L., Perry, R., Carruthers, L., Hawe, P., 2005. Introducing a means of quantifying community reputation: the print media as a data source. Health Place 11, 187-194.

Ott, S.A., Schalke, E., von Gaertner, A.M., Hackbarth, H., 2008. Is there a difference? Comparison of golden retrievers and dogs affected by breed-specific legislation regarding aggressive behavior. J. Vet. Behav. Clin. Appl. Res. 3, 134-140.

Ozanne-Smith, J., Ashby, K., Stathakis, V., 2001. Dog bite and injury prevention—analysis, critical review, and research agenda. Inj. Prev. 7, 321-326.

Parliament of Victoria, 2016. Inquiry into the Legislative and Regulatory Framework Relating to RestrictedBreed Dogs.

Podberscek, A.L., 1994. Dog on a tightrope: the position of the dog in British society as influenced by press reports on dog attacks (1988 to 1992). Anthrozoös 7, 232-241.

Raghavan, M., 2008. Fatal dog attacks in Canada, 1990-2007. Can. Vet. J. 49, 577.

Rock, M., Mykhalovskiy, E., Schlich, T., 2007. People, other animals and health knowledges: towards a research agenda. Soc. Sci. Med. 64, 1970-1976.

Rock, M.J., Adams, C.L., Degeling, C., Massolo, A., McCormack, G.R., 2014. Policies on pets for healthy cities: a conceptual framework. Health Promot. Int. 30 (no. 4), 976-986.

Súilleabháin, P.Ó., 2015. Human hospitalisations due to dog bites in Ireland (1998-2013): implications for current breed specific legislation. Vet. J. 204, 357-359.

Timmermans, S., Gabe, J., 2002. Introduction: connecting criminology and sociology of health and illness. Sociol. Health Illness 24, 501-516.

Tissot, S., 2011. Of dogs and men: the making of spatial boundaries in a gentrifying neighborhood. City Community 10, 265-284.

Toohey, A.M., Rock, M.J., 2011. Unleashing their potential: a critical realist scoping review of the influence of dogs on physical activity for dog-owners and non-owners. Int. J. Behav. Nutr. Phys. Act. 8, 46.

Toohey, A.M., Rock, M.J., 2015. Newspaper portrayals, local policies, and dog-supportive public space: who's wagging whom? Anthrozoös 28, 549-567.

Townshend, I., Miller, B., Evans, L., 2018. Socio-Spatial Polarization in an Age of Income Inequality: An Exploration of Neighbourhood Change in Calgary's "Three Cities". In: Neighbourhood Change Research Project Paper.

Wodak, R., Meyer, M., 2009. Methods for Critical Discourse Analysis. Sage. 